\title{
Self-regulation capacity is linked to wellbeing and burnout in physicians and medical students: Implications for nurturing self-help skills
}

\author{
Marie-Claude J. Gagnon · Natalie Durand-Bush · Bradley W. Young
}

\begin{abstract}
Self-regulation capacity relates to important self-help skills allowing individuals to effectively manage their thoughts, feelings, and actions to attain goals while mastering a demanding environment. The purpose of this study was to investigate the relationship between self- regulation capacity, psychological wellbeing, and burnout in 37 Canadian medical students and 25 physicians. Regression analyses showed that self-regulation capacity positively predicted psychological wellbeing and negatively predicted burnout for both groups. Concerning the dimensions of purpose in life and environmental mastery, the benefits of self-regulatory capacity were particularly pronounced for physicians. Implications for developing self-regulation competence to maintain optimal mental health are discussed.
\end{abstract}

Keywords: wellbeing, burnout, self-regulation, physicians, medical students

\section{Introduction}

The fast-pace changes and performance expectations within the medical community are not without consequences (Puddester, 2001; Wallace, Lemaire, \& Ghali, 2009). It appears that, while attempting to meet the demands of their profession, many physicians have lost sight of their wellbeing (Shanafelt, Sloan, \& Habermann, 2003), shaping the reality of today's "stressed out" (Canadian Medical Association (CMA), 2003), "burnt out” and/or dissatisfied physicians (Tyssen et al., 2009).

In light of the growing research exposing the reality of the "unwell" physician and medical student, and the potential negative consequences for patient care (Shanafelt et al., 2003), the Canadian Medical Association has made the development of sustainable and healthy physicians a priority (CMA, 2003). As a result, research on the causes and consequences of, and solutions to, physician burnout and distress has surged in the literature. While investigating treatment for physician distress and burnout is crucial, simply focusing on fixing the problem "is certainly settling for less than what can be achieved" (Shanafelt et al., 2003, p. 514). The tendency to focus on a disease model of health (Weiner, Swain, Wolfe, \& Gottlieb, 2001) and constantly reacting to obstacles and repairing what is wrong, does not seem to move us closer to the prevention of health-related problems. Based on the science of positive psychology, important insights into distress and burnout prevention have emerged from a perspective centered on proactively building strengths (Seligman \& Csikszentmihalyi, 2000). Human strengths and positive self-care strategies and skills are believed to act as buffers against the negative effects of stress and allow individuals to thrive and optimize their health and wellbeing. 
Unfortunately, researchers interested in the health and wellbeing of physicians and medical students have focused their efforts almost exclusively on "impairment" over the course of the last 40 years (Yamey \& Wilkes, 2001). As a result, they have given comparatively less attention to investigating the promotion and achievement of physician and medical student wellbeing through positive optimal functioning (Dyrbye, Thomas, \& Shanafelt, 2005; Shanafelt et al., 2003). Beyond measures of pathology (e.g., depression, anxiety), little is known about what it means for physicians and medical students "to be well," and, as such, their level of wellbeing measured from a positive psychological perspective remains unexplored (Shanafelt et al., 2003; Yamey \& Wilkes, 2001); consequently, more research is warranted.

Against this background, this study provides insight into the wellbeing and burnout levels of physicians and medical students, using a positive psychology perspective. Specifically, it examines whether self-regulation capacity can account for variation in these levels. Our goal was to examine associations between self-regulation capacity and levels for wellbeing and burnout, to further advance discussion on whether self-help means may moderate important indicators of health in physicians (e.g., Simon \& Durand-Bush, 2014).

\subsection{Burnout}

Practicing medicine entails facing many stressors (e.g., long hours, emotionally charged situations, difficult interactions, excessive cognitive demands, rapid changes in the profession) that can have a serious harmful effect on physicians' mental health, including burnout (Shanafelt et al., 2003; Wallace et al., 2009). A survey revealed that nearly two thirds (64\%) of Canada's physicians reported having a workload they considered too heavy, and more than half (58\%) of them stated that their family and personal life had suffered because they chose medicine as a profession.

Stress occurs when there is a substantial imbalance between demands and response capability under conditions where failure to meet the demands has important consequences (McGrath, 1970). Chronic manifestations of stress can lead to burnout (Maslach \& Leiter, 2008), which is characterized by emotional exhaustion, depersonalization, and a sense of low personal accomplishment. Burnout is disconcertingly reported to affect nearly half of the Canadian physician community (Boudreau, Grieco, Cahoon, Robertson, \& Wedel, 2006; Puddester, 2004). In addition to impacting physicians' mental health, distress and burnout appear to alter the quality of care they provide to their patients (Eckleberry-Hunt et al., 2009; Shanafelt, 2009; Taub, Morin, Goldrich, Ray, \& Benjamin, 2006). Similar results have been found in medical students, who reported high levels of stress throughout their training that can impede their performance, professionalism, and overall health (Dyrbye et al., 2005; Lee \& Graham, 2001). In fact, medical students have higher rates of psychological distress, and may also be more vulnerable to health problems than the general public and age-matched peers (Dyrbye et al., 2005). Failure to effectively cope with stress during medical training can lead to future personal impairment, as well as decreased performance as physicians (Estabrook, 2008).

\subsection{Wellbeing}

Several researchers have advocated that physician wellbeing is more than the absence of impairment and negative states (Shanafelt et al., 2003, Weiner et al., 2001; Yamey \& Wilkes, 2001). Consequently, it is important to investigate wellbeing from a positive perspective to gain insight into optimal functioning states and mental health. According to Keyes and Waterman (2003), wellbeing encompasses social, emotional, psychological, and physical aspects that help shape overall positive life functioning. Ryff and Keyes (1995) conducted instrumental research in the 
area of psychological wellbeing, and postulated that other aspects of positive functioning, beyond the hedonic dimension of feeling happy and satisfied with life (Diener, 2000), must be considered to obtain a comprehensive view of wellbeing. They generated a multidimensional model of psychological (eudaimonic) wellbeing that includes six distinct components: autonomy, environmental mastery, personal growth, positive relations with others, purpose in life, and self-acceptance. Ryff and Keyes' (1995) model has received wide support in the literature in studies of wellbeing (Abbott, Ploubidis, Huppert, Kuh, \& Croudace, 2010) across several domains including mental health (Negrini, Corbière, Fortin, \& Lecomte, 2014), health and aging (Brim, Ryff, \& Kessler, 2004; Clarke, Marshall, Ryff, \& Wheaton, 2001), body consciousness (McKinley, 1999), life challenges (McGregor \& Little, 1998), midlife work aspirations (Carr, 1997), and therapeutic interventions (Fava et al., 2005). To our knowledge, it has been used in only one other study to investigate the wellbeing of physicians, and this preliminary work showed promise that it is a valid model for examining wellbeing in this context (Simon \& Durand-Bush, 2014).

Overall, research has shown the positive effect of wellbeing on performance, productivity, mental and physical health, and relationships (Keyes \& Waterman, 2003). Individuals with higher levels of wellbeing tend to adopt more positive self-care behaviors and have fewer maladaptive lifestyle and health problems (Diener \& Ryan, 2009; Zimmerman, 2000). It would thus be valuable to examine the wellbeing of physicians in relation to positive outcomes, such as self-care capacity (e.g., self-regulation), as this could shed light on self-directed strategies they can use to manage their health.

\subsection{Self-Regulation}

Wellbeing has been linked to self-regulation capacity in several contexts (Elliot, Thrash, \& Murayama, 2011; Hofer, Busch, \& Kartner, 2011; Vohs \& Baumeister, 2004; Wrosch, Scheier, Miller, Schulz, \& Carver, 2003). Self-regulation reflects one's capacity to plan, control, evaluate, and adapt internal states in order to attain desired goals in changing and demanding environments (Zimmerman, 1996). More specifically, this skill entails setting standards for desired thoughts, feelings, and actions, along with outcome expectations, as well as monitoring and evaluating oneself to identify discrepancies and to adapt. Self-regulation has been recognized as one of 24 character strengths in the VIA (Values in Action) Inventory of Strengths, a positive psychology measure designed to identify a profile of an individual's character strengths (Peterson \& Seligman, 2004).

Zimmerman's (2000) social-cognitive perspective of self-regulation demonstrates how selfregulation capacity can be not only learned and retained, but also nurtured by external social agents. This intuitively lends itself to an understanding of developing and fostering healthy behaviors and achieving wellbeing in complex environments - it emphasizes the interaction between personal (e.g., cognitive, affective, behavioral) and environmental (e.g., social) processes. It suggests that individuals must develop and utilize their personal resources in order to effectively adapt to continuous changes in the environment (Zimmerman, 2000). Physicians and medical students training to become proficient health experts should therefore be viewed as active agents, managing their thoughts, feelings, and actions in order to adjust to the continually changing and taxing demands of their profession.

Although self-regulatory processes similar to those postulated by Zimmerman (2000) have been highlighted as effective means to enhance physician and medical student wellbeing and performance (e.g., self-reflection, Dobie, 2007; self-monitoring, Borrell-Carrió \& Epstein, 2004; Epstein, Siegal, \& Silberman, 2008; acceptance and regulation of personal limitations and 
standards, Meldrum 2010; regulation of attention and mindfulness, Baer, 2003; regulation of affect, Simon \& Durand-Bush, 2009), overall self-regulation as a skill or capacity involving a collection of self-management processes remains for the most part unexplored within the medical community.

Recently, Simon and Durand-Bush (2014) investigated whether or not self-regulation capacity could significantly predict psychological wellbeing in a sample of 132 Canadian physicians. They found that self-regulation capacity did, in fact, account for a significant amount of variance in all six dimensions of psychological wellbeing (Ryff \& Keyes, 1995). Self- regulation capacity had a strong positive relationship with environmental mastery and purpose in life, which suggested that effective self-management skills may help physicians to fulfill/balance tasks and maintain a sense of direction in their work. This study demonstrated an association between the aforementioned variables; however, it did not consider dual aspects of wellbeing and burnout, nor did it consider whether these associations are similar or different with respect to physicians and medical students. The current study extended the research and further aimed to determine if strengthening self-regulation capacity could contribute to physicians' health and address a priority of the CMA.

\section{Purpose of study and hypotheses}

The purpose of this study was to assess: (a) if self-regulation capacity could significantly predict levels of psychological wellbeing and of burnout among physicians and medical students, and (b) if group status (i.e., physician or medical student) moderated the association between selfregulation capacity and the predicted outcome variables. Based on evidence showing that effective self-regulation leads to optimal functioning and enhanced coping under stress and adversity (Bandura, 2005; Baumann, Kaschel, \& Kuhl, 2007; Elliot et al., 2011; Hofer et al., 2011; Vohs \& Baumeister, 2004, Zimmerman, 1996; Zimmerman, 2000), we hypothesized that selfregulation capacity would positively predict psychological wellbeing and negatively predict burnout. However, due to a lack of prior research and the exploratory nature of our analyses, no hypotheses were formulated for the moderating effect of group status on wellbeing and burnout outcomes.

\section{Methods}

\subsection{Participants}

Physicians involved in education and medical training, and medical students enrolled in the first, second, third, or fourth year of their medical program at a Canadian university participated in this study. Using a combination of availability and quota sampling techniques (Garson, 2009), participants were recruited via posters and emails sent by representatives from the targeted university's Faculty of Medicine and affiliated community hospitals. Ethics approval was obtained from the university, and participants provided their informed consent before completing the surveys. The sample included 37 medical students and 25 practicing physicians occupying educational and/or supervisory roles.

\subsection{Measures}

All participants were emailed a link that allowed them to independently access and complete an online survey that included four questionnaires and demographic questions. Completion of this survey took approximately 20 minutes. 


\subsubsection{Self-regulation capacity}

Self-regulation capacity was evaluated using the short form of the original Self-Regulation Questionnaire (SSRQ, Brown, Miller, \& Lawendowski, 1999). The SSRQ is a single factor, 31-item questionnaire that is scored using a 1 to 5 Likert scale ranging from "strongly disagree" to "strongly agree." It yields a total score that represents a low, intermediate, or high level of selfregulatory capacity. Cut-off values were adapted based on those from the original version, with a score of 118 or more reflecting high self-regulation capacity, a score between 105 and 117 reflecting a moderate capacity, and a score of less than or equal to 104 representing low selfregulation capacity. Items reveal cognitive, affective, behavioral and social/environmental aspects of self-regulation, as well as both proactive (e.g., planning and adjusting of goals) and reactive (e.g., responding to adversity) sub-processes. The SSRQ has been shown to have good psychometric properties in a series of studies on self-regulation and drinking behavior in college students (Hustad, Carey, Carey, \& Maisto, 2009).

\subsubsection{Wellbeing}

Wellbeing was assessed using Ryff and Keyes' (1995) Scales of Psychological Well-Being (SPWB). This comprehensive and psychometrically sound tool includes six 14-item scales measuring the following dimensions of psychological wellbeing: (a) autonomy (i.e., self-determination), (b) environmental mastery (i.e., capacity to effectively manage one's life and surrounding environment), (c) personal growth (i.e., continued growth and development as a person), (d) positive relations with others (i.e., quality relations with others), (e) purpose in life (i.e., belief that one's life is purposeful and meaningful), and (f) self-acceptance (i.e., positive evaluations of oneself and one's past life). Items are answered using a six-point Likert scale ranging from "strongly disagree" to "strongly agree," with higher scores reflecting a higher level of wellbeing for each dimension. No specific cut-off scores have been published.

\subsubsection{Burnout}

Burnout was measured using the Maslach Burnout Inventory (MBI, Schaufeli, Leiter, Maslach, \& Jackson, 1996). This 22-item standardized instrument includes three subscales evaluating: (a) emotional exhaustion (i.e., feelings of being overextended and depleted of one's emotional and physical resources), (b) depersonalization (i.e., negative detachment from various aspects of one's work, including people), and (c) personal accomplishment (i.e., feelings of competence and productivity regarding one's work) (Maslach \& Leiter, 2008). Responses are rated on a 7-point Likert scale ranging from 1 (never) to 7 (every day), and generate an individual score for each subscale. Cut-off scores for the means were taken from a normative sample of 1,104 health professionals in the United States (Thorten, Tharp, \& Meguid, 2011). Respondents are classified as having high, moderate or low burnout, and convention stipulates that a high degree of professional burnout is reflected by a high score on the depersonalization and the emotional exhaustion subscales, and a low score on personal accomplishment (Maslach \& Leiter, 2008). The MBI questionnaire has been used in a study in which burnout levels of physicians were measured (Dyrbye, Thomas, \& Shanafelt, 2006).

\subsection{Data analysis}

The questionnaire data were analyzed using the software program SPSS 11.0. Of the 62 participants, 62 completed the SSRQ, 60 completed the SPWB and 58 answered the MBI. We used a mean imputation to calculate missing data points for each scale, given that these represented 
less than $5 \%$ of the total data points. We computed internal consistency coefficients to examine the reliability of scales or subscales for each measure. We also obtained descriptive statistics to determine physicians and medical students' levels of self-regulation capacity, psychological wellbeing, and burnout. Pearson product-moment correlations allowed us to examine the strength of the relationships between the variables. Finally, we performed a series of hierarchical regressions to assess if self-regulation capacity could significantly predict psychological wellbeing and burnout, and if group status (i.e., physicians versus medical students) moderated these relationships.

\section{Results}

\subsection{Demographics}

An equal number of men $(n=31)$ and women $(n=31)$ participated in this study. Specifically, there were 17 male and 20 female medical students, and 14 male and 11 female physicians. The participants were aged between 21 and 70 years $(21-30 \mathrm{yrs}=69.4 \%$; $31-40 \mathrm{yrs}=12.9 \% ; 41-50 \mathrm{yrs}=$ $11.3 \% ; 51-70 \mathrm{yrs}=6.5 \%$ ) although a large proportion were in their 20s. Amongst the practicing physicians, there was a broad representation of specialties and domains of practice including anatomical pathology, cardiology, obstetrics and gynecology, emergency medicine, internal medicine, psychiatry, general surgery, anesthesia, radiation oncology, palliative medicine, orthopedic surgery, neurology, and family medicine.

\subsection{Internal consistency and descriptive statistics}

Cronbach's alpha coefficients for each scale or subscale are included in Table 1 below.

Table 1. Cronbach's alpha coefficients, means (M) and standard deviations (SD)

\begin{tabular}{|c|c|c|c|c|c|c|c|}
\hline \multirow{2}{*}{ Measures } & \multirow{2}{*}{$\begin{array}{c}\text { Cronbach's } \\
\text { Alpha }\end{array}$} & \multicolumn{2}{|c|}{ Both groups } & \multicolumn{2}{|c|}{ Physicians } & \multicolumn{2}{|c|}{ Students } \\
\hline & & $\mathbf{M}$ & SD & $\mathbf{M}$ & SD & $\mathbf{M}$ & SD \\
\hline \multirow[t]{2}{*}{ SSRQ } & 0.92 & \multicolumn{2}{|c|}{$\mathrm{n}=62$} & \multicolumn{2}{|c|}{$\mathrm{n}=25$} & \multicolumn{2}{|c|}{$\mathrm{n}=37$} \\
\hline & & 123.15 & 13.49 & 124.00 & 16.53 & 122.57 & 11.2 \\
\hline SPWB & & \multicolumn{2}{|c|}{$\mathrm{n}=60$} & \multicolumn{2}{|c|}{$\mathrm{n}=24$} & \multicolumn{2}{|c|}{$\mathrm{n}=36$} \\
\hline Autonomy & 0.76 & 57.77 & 9.26 & 60.58 & 9.38 & 55.89 & 8.81 \\
\hline Environmental Mastery & 0.80 & 59.18 & 9.63 & 60.79 & 12.55 & 58.11 & 7.06 \\
\hline Personal Growth & 0.83 & 62.73 & 10.54 & 67.54 & 10.41 & 59.53 & 9.47 \\
\hline Positive Relationships & 0.88 & 60.80 & 12.46 & 62.38 & 14.20 & 59.75 & 11.23 \\
\hline Purpose in Life & 0.89 & 60.13 & 14.28 & 67.67 & 14.21 & 55.11 & 12.98 \\
\hline Self-Acceptance & 0.89 & 59.88 & 13.26 & 64.75 & 15.62 & 56.64 & 10.43 \\
\hline MBI & & \multicolumn{2}{|c|}{$\mathrm{n}=58$} & \multicolumn{2}{|c|}{$\mathrm{n}=24$} & \multicolumn{2}{|c|}{$\mathrm{n}=34$} \\
\hline Emotional Exhaustion & 0.92 & 18.72 & 11.66 & 19.29 & 13.87 & 18.32 & 10.02 \\
\hline Depersonalization & 0.84 & 4.71 & 5.75 & 5.5 & 6.47 & 4.15 & 5.22 \\
\hline Personal Accomplishment & 0.82 & 39.24 & 6.41 & 39.58 & 7.74 & 39.0 & 5.38 \\
\hline
\end{tabular}

They ranged from 0.76 (good) to 0.92 (excellent) (George \& Mallery, 2003). The means and standard deviations for all 10 study variables (Table 1 above) were found to be normally distributed for all scales. The mean self-regulation capacity score for both groups was 123.15 (SD $=13.49$ ). Based on Brown et al.'s (1999) suggested cut-off scores for high, moderate, and low self- 
regulation capacity, 47 of the 62 participants $(76 \%)$ had high, eight participants had moderate $(13 \%)$, and seven had low (11\%) self-regulation capacity.

Mean scores ranging between 14 and 84 were obtained for each of the six dimensions of the SPWB. Following Ryff and Singer's (2006) guidelines, high scorers and low scorers on each dimension were delimited, based on the middle cut-off score of 49 . Mean scores for autonomy $(57.77, S D=9.26)$, environmental mastery $(59.18, S D=9.63)$, personal growth $(62.73, S D=10.54)$, positive relationships $(60.80, S D=12.46)$, purpose in life $(60.13, S D=14.28)$ and self- acceptance $(59.88, S D=13.26)$ were all above 49 , which indicates that the physicians and medical students had moderate to moderately high levels of wellbeing.

For the MBI questionnaire, emotional exhaustion subscale scores varied between 0 and 64, with subscale cut-off scores of high $\geq 27$, moderate 19-26 and low 0-18, where higher scores indicated higher levels of emotional exhaustion. Depersonalization subscale scores ranged from 0 to 30 , with subscale cut-off scores of high $\geq 10$, moderate 6-9, low $0-5$, where higher scores indicated higher levels of depersonalization. Finally, personal accomplishment subscale scores varied between 0 and 48, with subscale cut-off scores of high $\geq 40$, moderate 34-39, low 0-33, where lower scores represented reduced accomplishment. Overall mean scores for emotional exhaustion $(18.72, S D=11.66)$ and depersonalization $(4.71, S D=5.75)$ were considered to be in the low range, while the mean score for personal accomplishment $(39.24, S D=6.41)$ was considered to be in the high range, based on established cut-off scores (Thorten et al., 2011).

\subsection{Hierarchical regressions}

Separate hierarchical regression analyses served to explain variance in each psychological wellbeing dependent variable (i.e., six scales) and each burnout dependent variable (i.e., three subscales). We followed the same steps for entering blocks into the model for all hierarchical regressions. For each analysis, we entered variables in additive blocks as follows: (a) entered group status ( 0 for physicians, designated as "MD," 1 for medical students, designated as "STUD"); (b) added a centered variable for the total score on the SSRQ; and (c) added a crossproduct term to examine the interaction between group and the centered variable for SSRQ (see Holmbeck, 2002 for steps). To prepare for hierarchical regression analyses involving an interaction term, and to guard against multicollinearity, we first centered the SSRQ score before multiplying it by group to obtain the cross-product (see Cohen, Cohen, West, \& Aiken, 2003).

Table 2 below displays the results of the analyses pertaining to the wellbeing dependent variables, and Table 3 below presents those relating to the burnout dependent variables. We interpreted significant interactions between self-regulation capacity and a dependent variable (i.e., the association was unique to one group) when there was a significant regression model in step 3, when the model in step 3 explained significantly more variance than the model in step 2 (i.e., $p<.05$ for the $\Delta F$ statistic from model 2 to 3), and when the beta weight for the "status X SR" interaction term in model 3 was significant (Holmbeck, 2002). To confirm any significant interactions, we graphed figures and performed post-hoc tests of simple slopes (Tabachnick \& Fiddell, 2012). 
Table 2. Hierarchical regression analyses explaining variance in psychological wellbeing variables

\begin{tabular}{|c|c|c|c|c|c|c|}
\hline \multirow{2}{*}{ Block variables } & \multicolumn{3}{|c|}{ Autonomy } & \multicolumn{3}{|c|}{ Personal Growth } \\
\hline & $\operatorname{Adj} R^{2}$ & $p$ for $\Delta F$ & $B$ & $\operatorname{Adj} R^{2}$ & $p$ for $\Delta F$ & $B$ \\
\hline Step 1: Status & .04 & .05 & & $.12^{* *}$ & .003 & \\
\hline MD vs STUD & & & & & & $-.37^{* *}$ \\
\hline Step 2: Main effects & $.22^{* * *}$ & .000 & & $.36^{* * *}$ & .000 & \\
\hline MD vs STUD & & & -.22 & & & $-.35^{* *}$ \\
\hline SSRQ & & & $.43^{* * *}$ & & & $.49^{* * *}$ \\
\hline $\begin{array}{l}\text { Step 3: Interaction } \\
\text { MD vs STUD } \\
\text { SSRQ } \\
\text { Status X SR }\end{array}$ & $.20^{* *}$ & .71 & & $.37^{* *}$ & .17 & \\
\hline
\end{tabular}

\begin{tabular}{|c|c|c|c|c|c|c|}
\hline \multirow{2}{*}{ Block variables } & \multicolumn{3}{|c|}{ Positive Relationships } & \multicolumn{3}{|c|}{ Purpose in Life } \\
\hline & $\operatorname{Adj} R^{2}$ & $p$ for $\Delta F$ & $B$ & $\operatorname{Adj} R^{2}$ & $p$ for $\Delta F$ & $B$ \\
\hline Step 1: Status & .006 & .42 & & $.17^{* *}$ & .001 & \\
\hline MD vs STUD & & & & & & $-.43^{* *}$ \\
\hline Step 2: Main effects & $.19^{* * *}$ & .000 & & $.43^{* * *}$ & .000 & \\
\hline MD vs STUD & & & -.08 & & & $-.40^{* * *}$ \\
\hline SSRQ & & & $.46^{* * *}$ & & & $.51^{* * *}$ \\
\hline Step 3: Interaction & .21 & .17 & & $.47^{* * *}$ & .03 & \\
\hline MD vs STUD & & & & & & $-.40^{* * *}$ \\
\hline SSRQ & & & & & & $.68^{* * *}$ \\
\hline Status X SR & & & & & & $-.26^{*}$ \\
\hline \multirow{2}{*}{ Block variables } & \multicolumn{3}{|c|}{ Environmental Mastery } & \multicolumn{3}{|c|}{ Self-Acceptance } \\
\hline & $\operatorname{Adj} R^{2}$ & $p$ for $\Delta F$ & $B$ & $\operatorname{Adj} R^{2}$ & $p$ for $\Delta F$ & $B$ \\
\hline Step 1: Status & .002 & .29 & & $.07^{*}$ & .01 & \\
\hline MD vs STUD & & & & & & $-.30^{*}$ \\
\hline Step 2: Main effects & $.35^{* * *}$ & .000 & & $.41^{* * *}$ & .000 & \\
\hline MD vs STUD & & & -.10 & & & $-.27^{* *}$ \\
\hline SSRQ & & & $.59^{* * *}$ & & & $.58^{* * *}$ \\
\hline Step 3: Interaction & $.42^{* *}$ & .008 & & $.46^{* * *}$ & .01 & \\
\hline MD vs STUD & & & -.10 & & & $-.27^{* *}$ \\
\hline SSRQ & & & $.82^{* * *}$ & & & $.77^{* * *}$ \\
\hline Status X SR & & & $-.35^{* *}$ & & & $-.30^{*}$ \\
\hline
\end{tabular}

*** $p<.001 .{ }^{* *} p<.01{ }^{*} p<.05$.

Note. Beta weights are shown only for significant variable blocks that demonstrate greater variance explained ( $p$ for $\Delta F<.05$ ) than the prior variable block. 
Table 3. Hierarchical regression analyses explaining variance in burnout

\begin{tabular}{|c|c|c|c|c|c|c|}
\hline \multirow{2}{*}{ Block variables } & \multicolumn{3}{|c|}{ Emotional Exhaustion } & \multicolumn{3}{|c|}{ Depersonalization } \\
\hline & $\operatorname{Adj} R^{2}$ & $p$ for $\Delta F$ & B & $\operatorname{Adj} R^{2}$ & $p$ for $\Delta F$ & $B$ \\
\hline $\begin{array}{l}\text { Step 1: Status } \\
\text { MD vs STUD }\end{array}$ & .01 & .75 & & .04 & .38 & \\
\hline Step 2: Main effects & $.17^{* *}$ & .000 & & $.07^{*}$ & .01 & \\
\hline MD vs STUD & & & -.07 & & & -.13 \\
\hline SSRQ & & & $-.45^{* * *}$ & & & $-.30^{*}$ \\
\hline $\begin{array}{l}\text { Step 3: Interaction } \\
\text { MD vs STUD } \\
\text { SSRQ } \\
\text { Status X SR }\end{array}$ & $.19^{* *}$ & .16 & & .07 & .33 & \\
\hline
\end{tabular}

\begin{tabular}{lccc}
\hline \multirow{2}{*}{ Block variables } & \multicolumn{3}{c}{ Personal Accomplishment } \\
\cline { 2 - 3 } & Adj $R^{2}$ & $p$ for $\Delta F$ & $B$ \\
\hline Step 1: Status & -.01 & .73 & \\
MD vs STUD & & & \\
Step 2: Main effects & $.30^{* * *}$ & .000 & \\
MD vs STUD & & & -.008 \\
SSRQ & & & $-.56^{* * *}$ \\
Step 3: Interaction & $.29^{* * *}$ & .46 & \\
MD vs STUD & & & \\
SSRQ & & & \\
Status X SR & & & \\
\hline
\end{tabular}

Note. ${ }^{* * *} p<.001 .{ }^{* *} p<.01 .{ }^{*} p<.05$. Beta weights are shown only for significant variable blocks that demonstrate significantly greater variance explained ( $p$ for $\Delta F<.05)$ than the prior variable block.

\subsubsection{Main effects for self-regulation capacity}

For each analysis, we inspected for models that were significant at step 2, and that did not show greater significance explained at step 3 (see Tables 2 and 3). Results showing greater significance explained at step 3, which suggest possible interaction effects by group status, are explained in the section below. Results meeting criteria for a main effect suggested that the association between self-regulation capacity and a particular dependent variable was significant, irrespective of group status (i.e., the main effect was shared by MD and STUD participants alike).

Results showed main effects for three psychological wellbeing dependent variables. More specifically, self-regulation capacity significantly and positively predicted levels for personal growth $(B=.49)$, positive relationships with others $(B=.46)$, and autonomy $(B=.43)$. There were three main effects for each of the burnout dependent variables. Self-regulation capacity was significantly associated with personal accomplishment $(B=-.56)$, and inversely associated with emotional exhaustion $(B=-.45)$, and depersonalization $(B=-.30)$. These results confirm our hypotheses.

\subsubsection{Post-hoc probes for interactions by group}

In Table 2 above, results indicate three statistically significant interactions between group status and self-regulation capacity for environmental mastery, purpose in life, and self-acceptance. We conducted post-hoc tests of simple slopes to confirm the interaction effects. For self-acceptance, the test failed to confirm that this effect was contingent upon group status - the simple slope for 
both the MD $(t=6.25, p<.001)$ and the STUD group $(t=2.00, p=.04)$ was significantly different from zero. Consequently, results indicate a main effect for self-regulation capacity on the psychological wellbeing dimension of self-acceptance that is not unique to any one group. In the model for step 2, self-regulation capacity significantly and positively predicted levels for selfacceptance $(B=.58)$, irrespective of group status.

Post-hoc tests of simple slopes confirmed the interaction for environmental mastery. Specifically, self-regulation capacity significantly predicted increased levels of environmental mastery for individuals in the MD group, $t=6.42, p<.001$; however, this same association was not significant for individuals in the STUD group, $t=1.73, p=.08$. Figure 1A displays this interactive relationship. Likewise, self-regulation capacity was significantly associated with increased levels for purpose in life for individuals in the MD group, $t=5.57, p<.001$, but not for individuals in the STUD group, $t=1.81, p=.07$ (see Figure 1B).

Figure 1. Significant interactions between group status and self-regulation capacity on dimensions of psychological wellbeing for environmental mastery and purpose in life.

\section{A. Environmental Mastery}

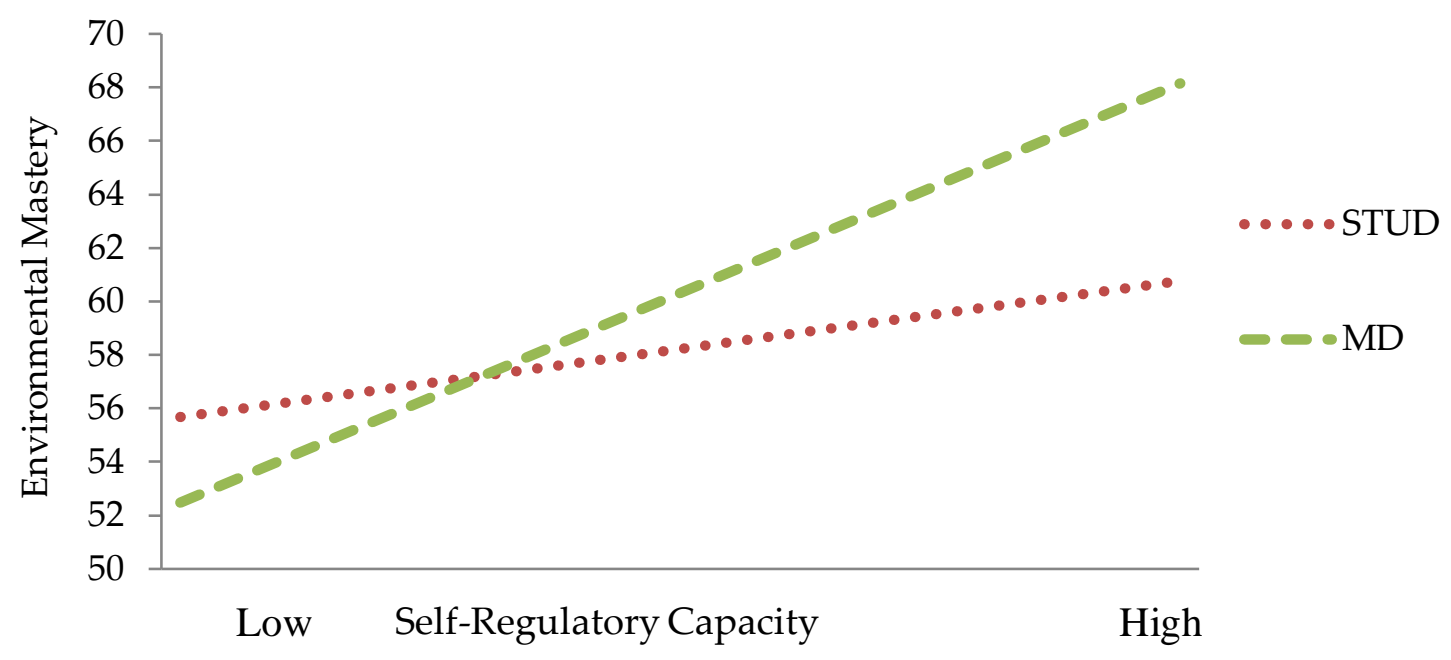

B. Purpose in Life

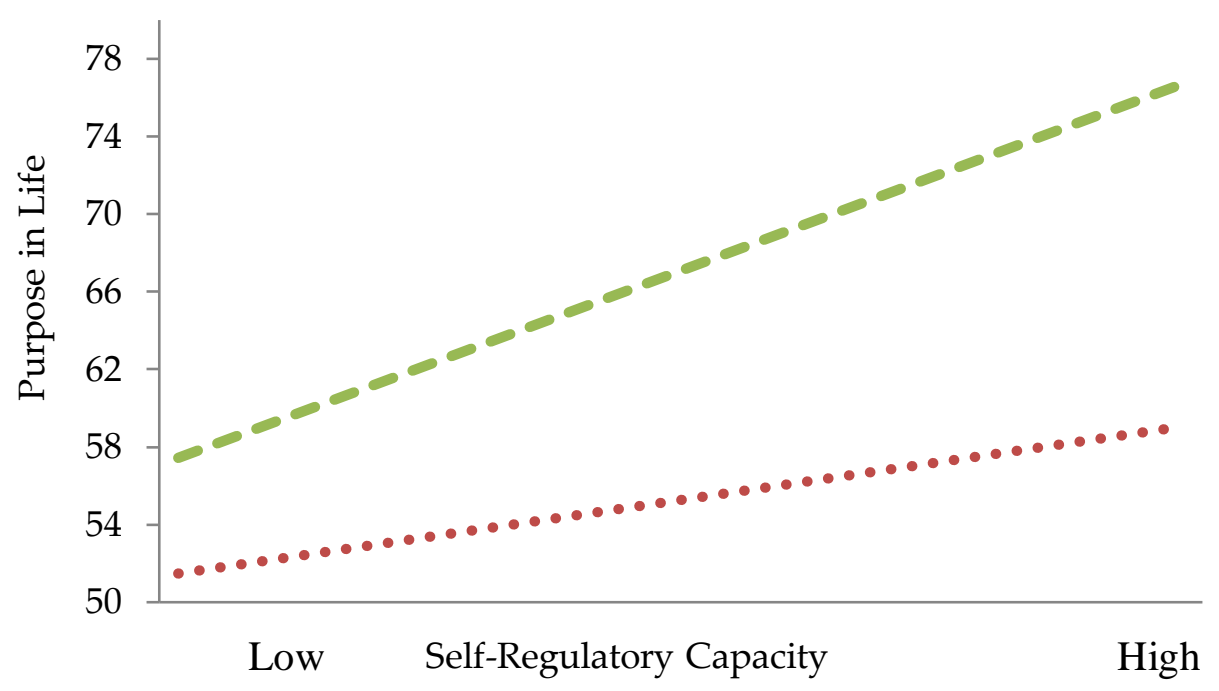




\section{Discussion}

Although self-management skills are deemed essential in the medical profession (Meldrum, 2010; Sotile \& Sotile, 2002), there is currently little empirical evidence that physicians and medical students can effectively self-regulate in order to pursue their goals, manage their stress and risk of burnout, and sustain adequate levels of wellbeing and mental health throughout the course of their career. The purpose of this cross-sectional study was to investigate the self-regulation capacity of physicians and medical students and establish if it is associated with lower levels of burnout and higher levels of psychological wellbeing.

Overall, the medical students and physicians had moderately high to high levels of selfregulation capacity, low to moderate levels of psychological wellbeing, and low levels of burnout. While these results are similar to those of Simon and Durand-Bush (2014), they are interestingly incongruent with some of the existing literature on physician wellbeing, in which it is argued that physicians are unwell and at high risk of burnout (Wallace et al., 2009). A possible explanation may be the participants' high self-regulation capacity, which has been associated with increased wellbeing and coping in academic domains (Boekaerts \& Corno, 2005; Hofer et al., 2011). Another possible explanation pertains to sampling and a self-selection bias in those people who volunteered to participate. The faculty from which the participants were recruited was unique in that it offered resources to develop self-care skills and achieve wellbeing goals, and many participants may have already accessed some of these resources and therefore had higher levels of self-regulation capacity and wellbeing. The participants' elevated levels should, however, not be considered in any normative way for physicians and medical students until significantly more work is done in this population of highly educated adult professionals to gain better profiling information.

With regards to associations between variables, results from the hierarchical regressions indicated a direct significant association between self-regulation capacity and all outcome variables. Irrespective of whether participants were physicians or medical students, having higher self-regulation capacity was associated with higher psychological wellbeing and less burnout. This supports Simon and Durand-Bush's (2014) findings regarding the potential power of self-regulation capacity to enhance physicians' psychological wellbeing. It also corroborates previous research in which effective self-regulation skills were found to be predictive of health, wellbeing, and performance achievement (Bandura, 2005; Zimmerman, 1996; 2000). Zimmerman (2000) suggested that proactively regulating desired feelings, thoughts, and actions can allow individuals to not only protect themselves against recurring stressors but also achieve desired wellbeing goals and standards. The statistically significant main effects of self-regulation capacity on the outcome variables support the hypothesis that developing self- regulation skills may be an effective approach to manage job-related stressors, promote positive mental health, and prevent mental health problems within the medical community.

The two identified interactive effects suggest that the benefits of having self-regulation capability may be particularly pronounced for physicians with regards to two dimensions of psychological wellbeing, that is, purpose in life and environmental mastery. This may mean that having greater self-management competencies may be particularly important to help physicians maintain a purposeful and meaningful life, and effectively manage the extensive personal and professional responsibilities they have in their daily life. Although the benefits of self-regulatory capacity are evident for medical students, they may not be as strong as those of physicians because they have limited control over their environment, due to mandated curriculum structure and training demands, and, as such, they may have less opportunity to enact their self-regulation competence to impact their environmental mastery. As for purpose in life, first and second-year 
medical students' direct patient care is limited, and, as a result, they may have fewer opportunities than physicians have to enact their self-regulation capacity to bolster their sense of purpose. For example, they likely have fewer occasions compared to physicians to develop meaningful interactions with patients or to take on meaningful mentoring roles. Environmental mastery and purpose in life could be key focus areas to target when developing self-help skills and strategies. However, more research with a larger number of participants is required to confirm these interactions and establish whether measurable differences exist between physicians and medical students and within the broader medical community.

In comparison to other predictors of psychological wellbeing and burnout that may be difficult to control (e.g., personality traits, imposed work conditions), self-regulation capacity is a skill under one's control that may be developed in order to manage inner states and adapt to one's environment. Self-regulation skills fluctuate over time and across contexts and may be particularly strained during times of duress (Zimmerman, 2000). As such, one can surmise that it would be beneficial to evaluate and nurture self-regulation skills as soon as students enter medical school. Practical workshops, seminars or retreats in which strategic planning, goalsetting, self-control, self-monitoring, and self-reflection strategies are refined could be provided for physicians throughout their career. Having a sense of control over one's practice environment was shown to be an important predictor of physician wellbeing, satisfaction, and commitment (Yamey \& Wilkes, 2001). Strengthening and empowering physicians to develop self-regulation skills that will impact how they manage their environment seems like a plausible and promising approach that should be further investigated.

\title{
6. Concluding remarks
}

This study is the first to measure self-regulation capacity in physicians and medical students and to explore its impact on psychological wellbeing and burnout. Irrespective of whether participants were physicians or medical students, higher self-regulation capacity was significantly associated with higher psychological wellbeing and less burnout. The benefits of high self-regulation competence may be particularly pronounced for physicians with regards to two dimensions of psychological wellbeing, that is, purpose in life and environmental mastery. These results hold important implications for understanding where and how to target future mental health and personal growth interventions within this community, if self-regulation is used as a self-care skill to enhance wellbeing.

The significant relationship between self-regulation capacity, psychological wellbeing and burnout is a promising finding that should be further explored, given the paucity of data, that may be used to enhance the mental health and wellbeing of Canadian physicians and medical students. Self-regulation may be a valuable self-help skill that physicians and medical students could learn early on in their training or career to manage the adversity they face and to optimize their performance in their environment. Given the mentoring role that physicians play in the education of medical students, it may be an asset for physicians to not only possess effective selfregulation skills but also have an ability to teach them to students during their training.

\author{
Authors \\ Marie-Claude J. Gagnon, M.D. \\ University of Ottawa \\ mcj_gagnon@hotmail.com
}


Natalie Durand-Bush, Ph.D.

University of Ottawa

Bradley W. Young, Ph.D.

University of Ottawa

\section{Publishing Timeline}

Received 8 April 2015

Accepted 23 August 2015

Published 14 May 2016

\section{References}

Abbott, R. A., Ploubidis, G. B., Huppert, F. A., Kuh, D., \& Croudace, T. J. (2010). An evaluation of the precision of measurement of Ryff's Psychological Well-Being Scales in a population sample. Social Indicators Research, 97(3), 357-373. http://dx.doi.org/10.1007/s11205-009-9506-x

Baer, R. A. (2003). Mindfulness training as a clinical intervention: A conceptual and empirical review. Clinical Psychology Science Practice, 10, 125-143. http://dx.doi.org/10.1093/clipsy.bpg015

Bandura, A. (2005). The primacy of self-regulation in health promotion. Applied Psychology: An International Review, 54(2), 245-254. http://dx.doi.org/10.1111/j.1464-0597.2005.00208.x

Baumann, N., Kaschel, R., \& Kuhl, J. (2007). Affect sensitivity and affect regulation in dealing with positive and negative affect. Journal of Research in Personality, 41, 239-248. http://dx.doi.org/10.1016/j.jp. 2006.05.002

Boekaerts, M., \& Corno, L. (2005). Self-regulation in the classroom: A perspective on assessment and intervention. Applied Psychology: An International Review, 54(2), 199-231. http://dx.doi.org/10.1111/j.1464-0597.2005.00205.x

Borrell-Carrió, F., \& Epstein, R. M. (2004). Preventing errors in clinical practice: A call for self-awareness. Annals of Family Medicine, 2, 310-316. http://dx.doi.org/10.1370/afm.80

Boudreau, R. A., Grieco, R. L., Cahoon, S. L., Robertson, R. C., \& Wedel, R. J. (2006). The pandemic from within: Two surveys of physician burnout in Canada. Canadian Journal of Community Mental Health, 25(2), 71-88. http://dx.doi.org/10.7870/cjcmh-2006-0014

Brim, O., Ryff, C. D., \& Kessler, R. C. (2004). How healthy are we? Chicago, IL: The University of Chicago Press.

Brown, J. M., Miller, W. R., \& Lawendowski, L. A. (1999). The self-regulation questionnaire. In L. VandeCreek \& T. L. Jackson (Eds.), Innovations in clinical practice: A sourcebook (pp. 281-292). Sarasota, FL: Professional Resource Press/Professional Resource Exchange.

Canadian Medical Association (2003). CMA guide to physician health and well-being: Facts, advice and resources for Canadian doctors. http://www.mtpinnacle.com/pdfs/guide-PHWB.pdf

Carr, D. (1997). The fulfillment of career dreams at midlife: Does it matter for women's mental health? Journal of Health and Social Behaviour, 38(4), 331-44. http://dx.doi.org/10.2307/2955429

Clarke P. J., Marshall, V. W., Ryff, C. D., \& Wheaton, B. (2001). Measuring psychological well-being in the Canadian Study of Health and Aging, International Psychogeriatrics, 13, 79-90. http://dx.doi.org/10.1017/S1041610202008013

Cohen, J., Cohen, P., West, S. G., \& Aiken, L. S. (2003). Applied multiple regression/correlation analysis for the behavioural sciences. Hillsdale, NJ: LEA.

Diener, E. (2000). Subjective well-being: The science of happiness and a proposal for a national index. American Psychologist, 55(1), 34-43. http://dx.doi.org/10.1037//0003-066X.55.1.34

Diener, E., \& Ryan, K. (2009). Subjective well-being: A general overview. South African Journal of Psychology, 39(4), 391-406. http://dx.doi.org/10.1177/008124630903900402

Dobie, S. (2007). Reflections on a well-traveled path: Self-awareness, mindful practice, and relationshipcentered care as foundations for medical education. Academic Medicine, 82(4), 422-427.

http://dx.doi.org/10.1097/01.ACM.0000259374.52323.62 
Dyrbye, L. N., Thomas, M. R., \& Shanafelt, T. D. (2005). Medical student distress: Causes, consequences, and proposed solutions. Mayo Clinic Proceedings, 80, 1613-1622. http://dx.doi.org/10.4065/80.12.1613

Dyrbye, L. N., Thomas, M. R., \& Shanafelt, T. D. (2006). Systematic review of depression, anxiety, and other indicators of psychological distress. Academic Medicine, 81, 354-373. http://dx.doi.org/10.1097/00001888-200604000-00009

Eckleberry-Hunt, J., Lick, D., Boura, J., Hunt, R., Balasubramaniam, M., Mulhem, E., \& Fisher, C. (2009). An exploratory study of resident burnout and wellness. Academic Medicine, 84, 269-277. http://dx.doi.org/10.1097/ACM.0b013e3181938a45

Elliot, A. J., Thrash, T. M., \& Murayama, K. (2011). A longitudinal analysis of self-regulation and wellbeing: Avoidance personal goals, avoidance coping, stress generation, and subjective well-being. Journal of Personality, 79, 3. http://dx.doi.org/10.1111/j.1467-6494.2011.00694.x

Epstein, R. M., Siegel, D. J., \& Silberman, J. (2008). Self-monitoring in clinical practice: A challenge for medical educators. Journal of Continuing Education in Health Professions, 28(1), 5-13. http://dx.doi.org/10.1002/chp.149

Estabrook, K. (2008). Medical student health promotion: The increasing role of medical schools. Academic Psychiatry, 32(1), 65-68. http://dx.doi.org/10.1176/appi.ap.32.1.65

Fava, G. A., Ruini, C., Rafanelli, C., Finos, L., Salmaso, L., Mangelli, L., \& Sirigatti, S. (2005). Well-being therapy of generalized anxiety disorder. Psychotherapy and Psychosomatics, 74(1), 26-30. http://dx.doi.org/10.1159/000082023

Garson, G. D. (2009). "Sampling," from Statnotes: Topics in Multivariate Analysis. http://faculty.chass.ncsu.edu/garson/PA765/statnote.htm

George, D., \& Mallery, P. (2003). SPSS for Windows step by step: A simple guide and reference (4th ed.). Boston, MA: Allyn \& Bacon.

Hofer, J., Busch, H., \& Kartner, J. (2011). Self-regulation and well-being: The influence of identity and motives. European Journal of Personality, 25, 211-224. http://dx.doi.org/10.1002/per.789

Holmbeck, G. N. (2002). Post-hoc probing of significant moderational and mediational effects in studies of pediatric populations. Journal of Pediatric Psychology, 27, 87-96. http://dx.doi.org/10.1093/jpepsy/27.1.87

Hustad, J. T. P., Carey, K. B., Carey, M. P., \& Maisto, S. A. (2009). Self-regulation, alcohol consumption, and consequences in college student heavy drinkers: A simultaneous latent growth analysis. Journal of Studies on Alcohol and Drugs, 70, 373-382. http://dx.doi.org/10.15288/jsad.2009.70.373

Keyes, C. L. M., \& Waterman, M. B. (2003). Dimensions of well-being and mental health in adulthood. In M. H. Bornstein, L. Davidson, C. L. M. Keyes, C. A. Moore (Eds.), Well- being: Positive development across the life course (pp. 477-495). Mahwah, NJ: Lawrence Erlbaum Associates.

Lee, J., \& Graham, A. V. (2001). Students' perception of medical school stress and their evaluation of a wellness elective. Medical Education, 35, 652-659. http://dx.doi.org/10.1046/j.1365-2923.2001.00956.x

Maslach, C., \& Leiter, M. P. (2008). Early predictors of job burnout and engagement. Journal of Applied Psychology, 93(3), 498-512. http://dx.doi.org/10.1037/0021-9010.93.3.498

McGrath, J. E. (1970). Major methodological issues. In J. E. McGrath (Ed.), Social and psychological factors in stress (pp. 19-49). New York, NY: Holt, Rinehart \& Winston.

McGregor, I., \& Little, B. R. (1998). Personal projects, happiness and meaning: On doing well and being yourself. Journal of Personality and Social Psychology, 74, 494-512. http://dx.doi.org/10.1037/00223514.74.2.494

McKinley, N. M. (1999). Women and objectified body consciousness: Mothers' and daughters' body experience in cultural, developmental, and familial context. Developmental Psychology, 35(3), 760-769. http://dx.doi.org/10.1037/0012-1649.35.3.760

Meldrum, H. (2010). Exemplary physician's strategies for avoiding burnout. The Health Care Manager, 29(4), 324-331. http://dx.doi.org/10.1097/HCM.0b013e3181fa037a

Negrini, A., Corbière, M., Fortin, G., \& Lecomte, T. (2014). Psychosocial well-being construct in people with severe mental disorders enrolled in supported employment programs. Community Mental Health Journal, 50(8), 932-942. http://dx.doi.org/10.1007/s10597-014-9717-8 
Peterson, C., \& Seligman, M. E. P. (2004). Character strengths and virtues: A handbook and classification. Washington, DC: APA Press.

Puddester, D. (2001). The Canadian Medical Association's policy on physician health and well-being. Western Journal of Medicine, 174(1), 5-7. http://dx.doi.org/10.1136/ewjm.174.1.5

Puddester, D. (2004). Canada responds: An explosion in doctors' health awareness, promotion and intervention. Medical Journal of Australia, 181(7), 386-387.

Ryff, C. D., \& Keyes, C. L. (1995). The structure of psychological well-being revisited. Journal of Personality and Social Psychology, 69(4), 719-27. http://dx.doi.org/10.1037/0022-3514.69.4.719

Ryff, C. D., \& Singer, B. H. (2006). Best news yet on the six-factor model of well-being. Social Science Research, 35, 1103-1119. http://dx.doi.org/10.1016/j.ssresearch.2006.01.002

Schaufeli, W. B., Leiter, M. P., Maslach, C., \& Jackson, S. E. (1996). The MBI-General Survey. In C. Maslach, S. E. Jackson, \& M. P. Leiter (Eds.), Maslach Burnout Inventory Manual (3rd ed., pp. 19-26). Palo Alto, CA: Consulting Psychologists Press.

Seligman, M. E., \& Csikszentmihalyi, M. (2000). Positive psychology: An introduction. American Psychologist, 55(1), 5-14. http://dx.doi.org/10.1037/0003-066X.55.1.5

Shanafelt, T. D. (2009). Enhancing meaning in work: A prescription for preventing physician burnout and promoting patient-centered care. Journal of the American Medical Association, 302(12), 1338-1340. http://dx.doi.org/10.1001/jama.2009.1385

Shanafelt, T. D., Sloan, J. A., \& Habermann, T. M. (2003). The well-being of physicians: Association of professors of medicine. The American Journal of Medicine, 114, 513-519. http://dx.doi.org/10.1016/S0002-9343(03)00117-7

Simon, C. R., \& Durand-Bush, N. (2009). Learning to self-regulate multi-dimensional felt experiences: The case of four female medical students. International Journal of Qualitative Studies on Health and Wellbeing, 4(4), 228-244. http://dx.doi.org/10.3109/17482620903116206

Simon, C. R., \& Durand-Bush, N. (2014). Does self-regulation capacity predict psychological well-being in physicians? Psychology, Health \& Medicine, 20(3), 311-321. http://dx.doi.org/10.1080/13548506.2014.936887

Sotile, W. M., \& Sotile, M. O. (2002). The resilient physician: Effective emotional management for doctors and their medical organizations. Chicago, IL: The American Medical Association.

Tabachnick, B. G., \& Fidell, L. S. (2012). Using multivariate statistics (6th ed.). Boston, MA: Pearson.

Taub, S., Morin, K., Goldrich, M. S., Ray, P., \& Benjamin, R. (2006). Physician health and wellness. Occupational Medicine, 56, 77-82. http://dx.doi.org/10.1093/occmed/kqj025

Thorten, V. C., Tharp, A. L. T., \& Meguid, T. (2011). High rates of burnout among maternal health staff at a referral hospital in Malawi: A cross-sectional study, BioMed Central Nursing, 10(9), 1-7.

Tyssen, R., Hem, E., Gude, T., Gronvold, N. T., Ekeberg, O., \& Vaglum, P. (2009). Lower life satisfaction in physicians compared with a general population sample: A 10-year longitudinal, nationwide study of course and predictors. Social Psychiatry and Psychiatric Epidemiology, 44, 47-54. http://dx.doi.org/10.1007/s00127-008-0403-4

Vohs, K. D., \& Baumeister, R. F. (2004). Understanding self-regulation: An introduction. In R. F. Baumeister, \& K. D.Vohs (Eds.), Handbook of self-regulation: Research, theory, and applications (pp. 1-12). New York, NY: The Guilford Press.

Wallace, J. E., Lemaire, J. B, \& Ghali, W. A. (2009). Physician wellness: A missing quality indicator. Lancet, 374, 1714-1721. http://dx.doi.org/10.1016/S0140-6736(09)61424-0

Weiner, E. L., Swain, G. R., Wolf, B., \& Gottlieb, M. (2001). A qualitative study of physicians' own wellness-promotion practices. Western Journal of Medicine, 174(1), 19-23. http://dx.doi.org/10.1136/ewjm.174.1.19

Yamey, G., \& Wilkes, M. (2001). Promoting wellbeing among doctors. British Medical Journal, 322, 252253. http://dx.doi.org/10.1136/bmj.322.7281.252

Zimmerman, B. J. (1996). Enhancing student academic and health functioning: A self-regulatory perspective. School Psychology Quarterly, 11(1), 47-66. http://dx.doi.org/10.1037/h0088920 
Zimmerman, B. J. (2000). Attaining self-regulation: A social cognitive perspective. In M. Boekaerts, P. R. Pintrich, \& M. Zeidner (Eds.), Handbook of self-regulation (pp. 13-42). San Diego, CA: Academic Press. http://dx.doi.org/10.1016/b978-012109890-2/50031-7 